\title{
On the Fatigue Strength of Steels Composed of Two Ductile Phases*
}

\section{By Yō TOMOTA,** Nobuyoshi TACHIBANA ${ }^{* * *}$ and Kōshiro KUROKI**}

\section{Synopsis}

Fatigue strength of two-ductile-phase steels is studied in order to clarify the effects of volume fraction of the harder phase $(f), C^{*}$-value $(=0.2 \%$ proof stress of the harder phase $10.2 \%$ proof stress of the softer phase), and the shape of the harder phase grain on fatigue properties. The alloys used are classified into three groups with various values of $f: \mathrm{Fe}-\mathrm{Cr}$ $\mathrm{Ni}$ alloys composed of austenite and ferrite $(A), \mathrm{Fe}-\mathrm{C}$ steels composed of ferrite and martensite $(C)$, and $\mathrm{Fe}-\mathrm{Cr}-\mathrm{Ni}$ alloys composed of austenite and martensite $(D)$. The value of $C^{*}$ is changed by aging $(A)$ or tempering $(C)$. The mean grain size $(\bar{d})$ of each alloy is adjusted to be nearly the same by heat treatments. The main results obtained are as follows.

(1) When the shape of grains (both of the harder phase and of the softer phase) is nearly spherical, the effects of $f, C^{*}$, and $\bar{d}$ are as follows.

(i) Effect of $f$ when $\bar{d}$ is constant: Three regions are observed in the relationship of endurance limit $\left(\sigma_{\mathrm{w}}\right)$ vs. $f$. Namely, according to an increase in $f, \sigma_{\mathrm{w}}$ hardly changes at first (1st region), then increases rapidly (2nd region), and ceases to change (3rd region).

(ii) Effect of $C^{*}$ : When alloys belong to the 1st region, $\sigma_{\mathrm{w}}$ is independent of $C^{*}$-value, while $\sigma_{\mathrm{w}}$ increases with an increase in the strength of tine harder phase $\left(C^{*}\right)$ in an alloy of the 2 nd or the $3 r d$ region.

(iii) Effect of $\bar{d}$ : $\sigma_{\mathrm{w}}$ is estimated to increase with decreasing $\bar{d}$, which plays an important role to obtain a two-phase alloy having excellent fatigue strength.

(2) In case of thin plate-like grain of the harder phase, $\sigma_{\mathrm{w}}$ increases with an increase in $f$ even if $f$ is small. That is, the range of each region mentioned above is changed by the shape of the harder phase.

(3) The above conclusions (I) and (2) are explained qualitatively by the observed preferential path of fatigue crack growth.

(4) The rate of crack growth at the 2 nd stage measured in notched specimens depends on $C^{*}$ even in alloys of the 1st region. This is also ascribed to the path of crack growth.

\section{Introduction}

The tensile properties of two-ductile-phase alloys have been studied in these years. ${ }^{1-7)}$ The characteristic deformation behavior of these alloys is due to the inhomogeneous distribution of plastic strain between two constituent phases. The degree of this inhomogeneity depends on several factors mentioned later. The discontinuity of plastic strain yields internal stress which can be divided into the average internal stress in each phase and locally fluctuating one. The former can be cheked by $\mathrm{X}$ ray stress measurement ${ }^{8,9)}$ and plays an important role in the deformation. ${ }^{4}$ Standing on this point, the effect of several factors on the tensile properties of two-ductile-phase alloys can be understood.

On the other hand, the fatigue properties of this type alloys, such as ferritic-pearlitic carbon steels, $\alpha-$ $\gamma$ stainless steels, and ferritic-martensitic steels, have also been reported. ${ }^{10-16)}$ These results show that the fatigue properties must be controlled by following factors, quite similar to the case of static deformation. ${ }^{2)}$ Namely,

1) Volume fraction of the harder phase $(f)$

2) Grain size ( $\bar{d}$ was defined as the value averaged with weight of $\left.f .{ }^{2 \prime}\right)$

3) Shape of grain

4) Strength of interface

5) Difference in mechanical properties, particularly the ratio of $0.2 \%$ proof stress between two constituent phases, $C^{*}\left(\sigma_{0.2}^{\mathrm{II}} / \sigma_{0.2}^{\mathrm{I}}\right)$, the importance of which was firstly emphasized by Tamura, et al. in tensile deformation. ${ }^{2}$ )

However, concerning the effects of these factors, some confusions have still been remained and clear understanding is not obtained yet. For instance, Hayden and Floreen ${ }^{10)}$ reported that the maximum endurance limit could be obtained at a certain value of $f$ and that fatigue properties of two-phase alloys were superior to those of single-phase ones. At a glance, it seems to be inconsistent with other reports. ${ }^{11-14)}$ Their data are believed to result from the confusion with respect to the effects of $f$ and $\bar{d}$. Therefore, it is important to clarify the effects of the above factors on fatigue properties independently and to explain the results on the same point of view.

The inhomogeneous plastic deformation must play a significant role in cyclic deformation as well as in monotonic tensile deformation and Bauschinger effect. ${ }^{17)}$ In this paper, the fracture process by fatigue is shown and the effects of several factors, mainly $C^{*}$ and $f$ are discussed from the standpoint of inhomogeneous deformation and preferential path of crack growth.

\section{Experimental Procedure}

The alloys used in this investigation are classified into three groups, namely austenitic-ferritic $\mathrm{Fe}-\mathrm{Cr}-$ $\mathrm{Ni}$ alloys (A), ferritic-martensitic Fe-C alloys (C) and austenitic-martensitic $\mathrm{Fe}-\mathrm{Cr}-\mathrm{Ni}$ alloys (D). ${ }^{\dagger}$ Alloys-groups A and D were prepared by vacuum induction melting and alloy-group $\mathrm{C}$ was commercially acquired. The chemical compositions of these alloys are shown in Table 1. They were hot-forged and cold-rolled to produce 2, 3 or $4 \mathrm{~mm}$ thick sheets. Then, specimens for fatigue test were machined par-

* Most part of this paper was originally published in Tetsu-to-Hagané, 63 (1977), 962, in Japanese. English version received May 11, 1977.

** Faculty of Engineering, Ibaraki University, Nakanarusawamachi, Hitachi 316.

*** Graduate School, Ibaraki University, Nakanarusawamachi, Hitachi 316.

$\dagger \quad$ The same symbols for alloys in the previous reports ${ }^{2,3}$ are used in this paper, 
Table 1. Chemical compositions of specimens (wt \%)

\begin{tabular}{|c|c|c|c|c|c|c|c|c|c|}
\hline Alloy symbol & $\mathrm{C}$ & $\mathrm{Si}$ & $\mathrm{Mn}$ & $P$ & $\mathrm{~S}$ & $\mathrm{Ni}$ & $\mathrm{Cr}$ & $\mathrm{Fe}$ & $f^{*}$ \\
\hline A 1 & 0.009 & 0.02 & 0.005 & 0.002 & 0.016 & 17.64 & 20.41 & bal. & 0.0 \\
\hline A 2 & 0.03 & 0.006 & 0.011 & 0.002 & 0.010 & 13.65 & 24.25 & bal. & 0.32 \\
\hline A 4 & 0.02 & 0.02 & 0.005 & 0.002 & 0.010 & 7.84 & 29.65 & bal. & 0.67 \\
\hline A 5 & 0.02 & 0.03 & 0.005 & 0.002 & 0.007 & 4.26 & 32.80 & bal. & 1.0 \\
\hline C 3 & 0.19 & 0.51 & 0.009 & 0.30 & 0.013 & - & - & bal. & 0.44 \\
\hline $\mathrm{C} 4$ & 0.33 & 0.72 & 0.013 & 0.34 & 0.021 & $\longrightarrow$ & $\longrightarrow$ & bal. & 0.78 \\
\hline $\mathrm{D}$ & $\underline{-}$ & 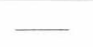 & 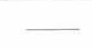 & 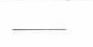 & - & 9.91 & 15.07 & bal. & - \\
\hline
\end{tabular}

$f^{*}$ : volume fraction of the harder phase of specimens
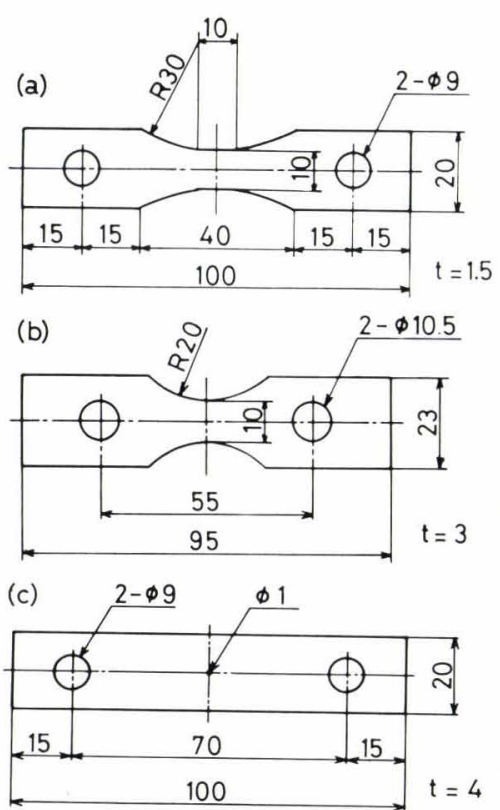

(b) Plain specimen for bending

(c) Notched specimen for pulsating tension

Fig. 1. Shapes and dimentions of specimens

allel to the rolling direction of the sheets. The shapes and dimensions of specimens are shown in Fig. 1. Plain specimens were used to obtain $\mathrm{S}-\mathrm{N}$ curves and central notched specimens were used to measure the growth rate of fatigue crack. The following heat treatments were adopted for each alloy. The detail of heat treatments and tensile properties of alloy-groups $\mathrm{A}$ and $\mathrm{C}$ were reported in the previous paper. ${ }^{2)}$

(1) Ferritic-Austenitic $\mathrm{Fe}-\mathrm{Cr}-\mathrm{Ni}$ alloys (A)

In order to obtain specimens with nearly same grain size, four kinds of alloys, that is, Al, A2, A4 and A5 were annealed at $1020^{\circ} \mathrm{C}$ for $1 \mathrm{hr}$, at $1125^{\circ} \mathrm{C}$ for $1 \mathrm{hr}$, at $1070^{\circ} \mathrm{C}$ for $2 \mathrm{hr}$, and at $750^{\circ} \mathrm{C}$ for $0.5 \mathrm{hr}$, respectively, in vacuum and then quenched into water. The specimens then resulted to have nearly the same $\bar{d}(15 \mu \mathrm{m})$ and different $f, 0(\mathrm{~A} 1), 0.32$ (A2), 0.67 (A4) and 1.0(A5). The half of quenched specimens were aged at $480^{\circ} \mathrm{C}$ for $100 \mathrm{hr}$. Only ferrite phase was hardened by aging. The values of $C^{*}$ were 3.1 for quenched specimens and 6.5 for quenchaged ones.

(2) Ferritic-Martensitic Fe-C alloys (C)

After austenitized at $1150^{\circ} \mathrm{C}$ for $5 \mathrm{hr}$ (C3) or at $1190^{\circ} \mathrm{C}$ for $12.5 \mathrm{hr}$ (C4), specimens were cooled to $785^{\circ} \mathrm{C}$, held there for $1 \mathrm{hr}$ and then quenched into water. By these heat treatments, two-phase alloys having $f$ of 0.44 (C3) or 0.78 (C4) were obtained. Then they were tempered at $200^{\circ} \mathrm{C}$ or $600^{\circ} \mathrm{C}$ for $1 \mathrm{hr}$. The value of $C^{*}$ was $6.7\left(200^{\circ} \mathrm{C}\right)$ or $4.5\left(600^{\circ} \mathrm{C}\right)$.

(3) Austenitic-Martensitic $\mathrm{Fe}-\mathrm{Cr}-\mathrm{Ni}$ alloys (D)

The specimens were annealed at $950^{\circ} \mathrm{C}$ for $0.5 \mathrm{hr}$ and then quenched into oil. The specimens were of single austenitic structure at room temperature. When they were cooled to $-196^{\circ} \mathrm{C}$ (liquid nitrogen) $\alpha^{\prime}$ and $\varepsilon^{\prime}$ martensites were produced as shown in Photo. 1 (h). According to the results of X-ray analysis, $f$ of $\alpha^{\prime}$ was about 0.3 and $f$ of $\varepsilon^{\prime}$ was little. The shape of the harder phase (aggregation of $\alpha^{\prime}$ and $\varepsilon^{\prime}$ ) is quite different from those of other alloys as can be seen in Photo. 1.

$\bar{d}$ and $f$ were determined by means of linear analysis on optical micrographs. ${ }^{2)}$

All specimens were mechanically and electrically polished prior to the test. The fatigue tests were carried out by tension-compression type fatigue testing machine (1 $800 \mathrm{rpm}$ ) for specimens of Figs. 1 (a) and (c) (pulsating tension), or by bending type testing machine $(2000 \mathrm{rpm}$ ) for the specimen of Fig. 1 (b) which was used only for the plain specimens of alloygroup C. Measurements of crack length were carried out by stroboscopic photographs during fatigue test for alloy C3. Fracture surfaces were observed by scanning electron microscopy.

\section{Experimental Results and Discussions}

1. Effects of Several Factors on Fatigue Strength

\section{Effect of $f$}

$\mathrm{S}-\mathrm{N}$ curves of quench-aged alloy-group $A$ are shown in Fig. 2 under the condition of nearly the same $\bar{d}$. Little difference can be found between $\mathrm{S}-$ $\mathrm{N}$ curve of $\mathrm{Al}(f=0)$ and that of $\mathrm{A} 2(f=0.32)$, or between $\mathrm{A} 4(f=0.67)$ and $\mathrm{A} 5(f=1.0)$. When the stress amplitude at $10^{7}$ cycles in $\mathrm{S}-\mathrm{N}$ curve is regarded as endurance limit $\left(\sigma_{\mathrm{w}}\right)$, the relation between $f$ and $\sigma_{\mathrm{w}}$ shown in Fig. 3 (a) is different from the results of Hayden and Floreen, (Fig. 3 (b)). ${ }^{10)}$ This inconsistency in $\sigma_{\mathrm{w}}$ is. $f$ relationship must be ascribed to the effect of $\bar{d}$. In the experiment by Hayden and Floreen, the value of $\bar{d}$ in two-phase alloys was much smaller than that of single-phase ones, while the alloys used in this experiment have nearly the same value of $\bar{d}$. Concerning the effect of $\bar{d}$, Ogiyama et al. ${ }^{15)}$ clarified 


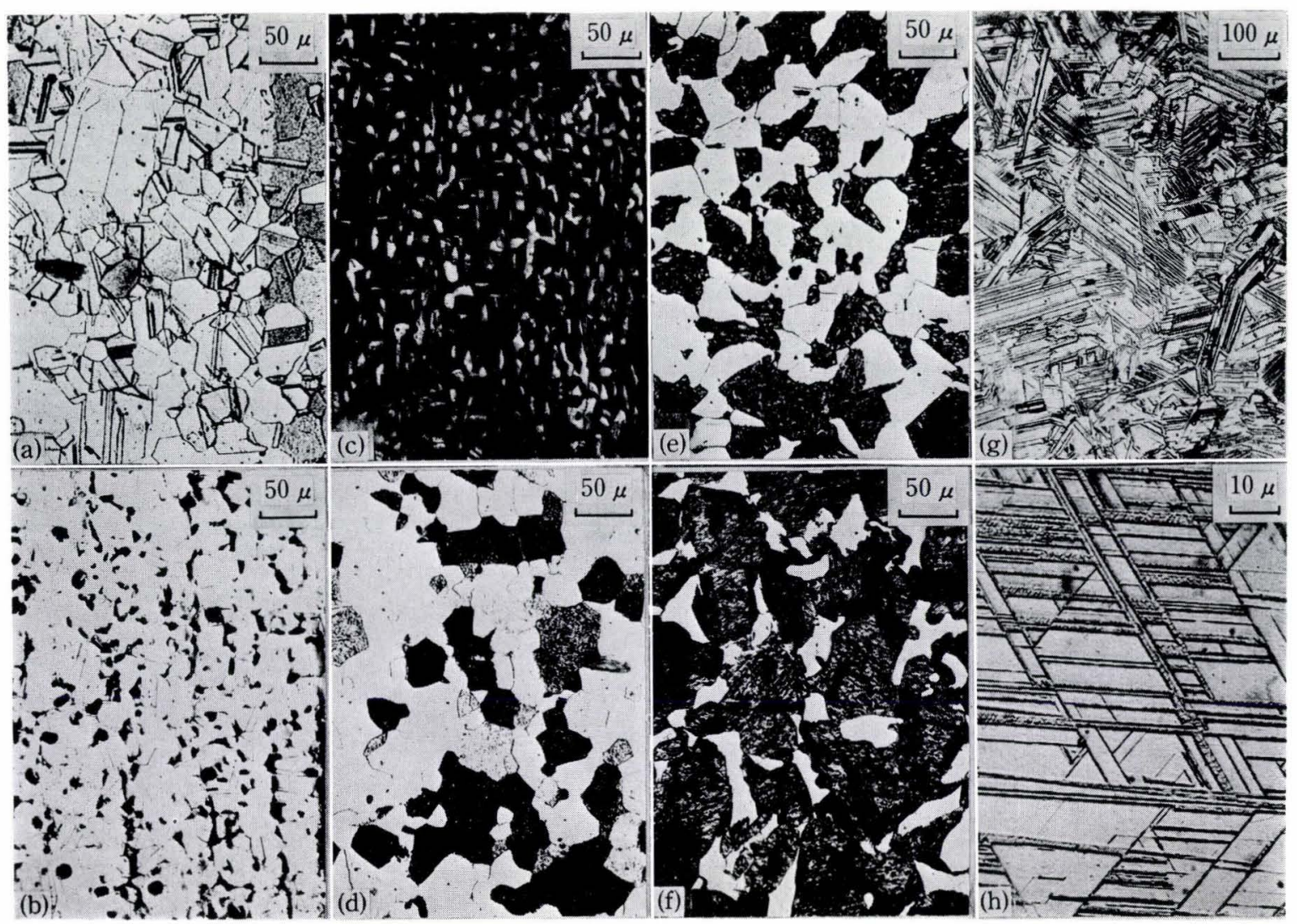

Photo. 1. Optical micrographs of specimens: (a) A1, (b) A2, (c) A4, (d) A5, (e) C3, (f) C4, and (g), (h) D

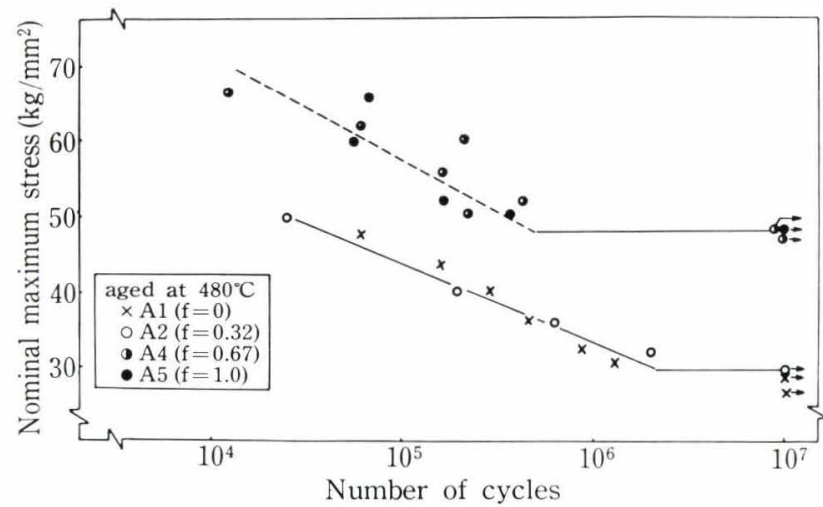

Fig. 2. S-N curves of alloy-group $\mathrm{A}$ (quench-aged specimens)

that $\sigma_{\mathrm{w}}$ was increased with decreasing $\bar{d}$ and that $\sigma_{\mathrm{w}}$ was about half of $\sigma_{0 \cdot 2}$. The effect of $\bar{d}$ on $\sigma_{0 \cdot 2}$ can be expressed by Petch's equation, i.e., $\left(\sigma_{0}+k \bar{d}^{-1 / 2}\right)$ where $\sigma_{0}$ and $k$ are constants. ${ }^{2)}$ Thus, fine grain size is believed to be important to obtain a two-phase alloy having excellent fatigue properties.

Then, it can be supposed that $\sigma_{\mathrm{w}}$ vs. $f$ relation is divided into three regions in Fig. 3 (a), that is,

lst region: For small $f$, the change of $\sigma_{\mathrm{w}}$ with the increase of $f$ is insignificant.

2nd region: $\sigma_{\mathrm{w}}$ increases with the increase of $f$.

3rd region: For large $f, \sigma_{\mathrm{w}}$ ceases to change with the increase of $f$.

According to the above division, some debates on $\sigma_{\mathrm{w}}$ of two-phase alloys can be focused. For example, next two experimental reports seem to belong to the debate of the 1 st region.

(1) It is well known that $\sigma_{\mathrm{w}}$ is hardly changed

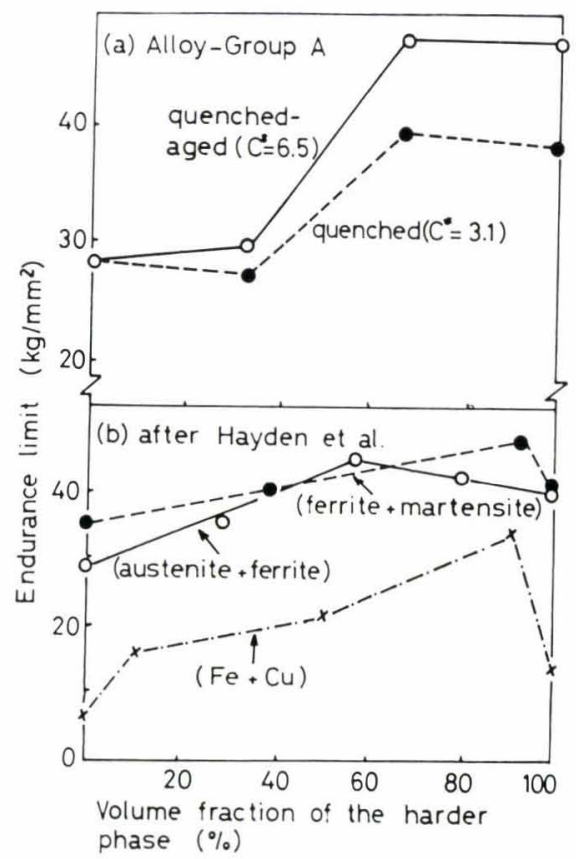

(a) Alloy-group $\mathrm{A}$

(b) After Hayden and Floreen ${ }^{11}$

Fig. 3. Relationships between endurance limit $\left(\sigma_{\mathrm{w}}\right)$ and volume fraction of the harder phase $(f)$

with increasing carbon content, i.e., $f$ of pearlite, in low carbon steels. ${ }^{12)}$

(2) Little difference could be found between $\sigma_{\mathrm{w}}$ of an alloy with $f=0$ and that of an alloy with $f=0.69$ in an austenitic-martensitic $\mathrm{Fe}-\mathrm{Ni}-\mathrm{C}$ steels. ${ }^{13)}$

On the other hand, the results on induction hard- 
ened low carbon steel containing retained ferrite by Yamada et al. ${ }^{11)}$ seem to be the debate in the 3rd region. The effect of retained austenite on $\sigma_{\mathrm{w}}$ of martensitic steels has been widely discussed and various results have been reported. ${ }^{14)}$ It seems to be the debate in the 2 nd or the 3 rd region.

The transition value of $f$ in each region may be influenced by shape or distribution of the harder phase. The reason why those regions exist is connected with the preferential path of fatigue crack propagation, the detail of which will be described in III. 2.

\section{Effect of $C^{*}$}

Figure 3 (a) shows the effect of $C^{*}$ on $\sigma_{\mathrm{w}}$ vs. $f$ relation. The $\sigma_{\mathrm{w}}$ is increased by aging in alloys A4 $(f=0.67)$ and A5 $(f=1.0)$ while $\sigma_{\mathrm{w}}$ is hardly changed in alloys $\mathrm{A} 1(f=0)$ and $\mathrm{A} 2(f=0.32)$. The difference between quenched specimens and quenchaged ones is only the strength of ferrite $\left(C^{*}\right)$.

In Fig. $4, \sigma_{\mathrm{w}}$ of $\mathrm{C} 3(f=0.44)$ is independent of the tempering temperature which influences the strength of martensite $\left(C^{*}\right)$. When $f$ increases to $0.78(\mathrm{C} 4), \sigma_{\mathrm{w}}$ becomes higher than that of C3.

Judging from these results, it may be imagined that $\sigma_{\mathrm{w}}$ of a two-phase alloy in the 1st region is not affected by $C^{*}$ while $\sigma_{\mathrm{w}}$ of a two-phase alloy in the 2nd or the 3rd region increases with increasing $C^{*}$. This can be also justified from the characteristics of fatigue crack growth described later.

\section{Effect of the Shape of the Harder Phase}

The results of alloy D are shown in Fig. 5. The shape of the harder phase in alloy D is somewhat different from that of alloy-group A or C (see Photo. 1). The $\sigma_{\mathrm{w}}$ of a two-phase alloy with $f=0.3$ is larger than that of single austenitic alloy $(f=0) .^{*}$ Thus, this two-phase alloy seems to belong to the 2 nd region, although in the case of alloy-groups $\mathrm{A}$ and $\mathrm{C}$, a twophase alloy with $f=0.3$ is regarded to belong to the

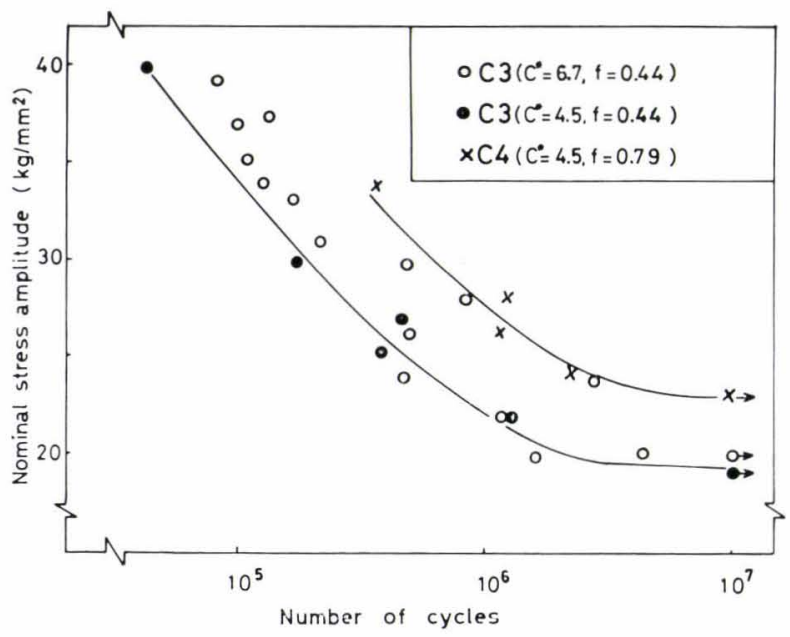

Fig. 4. S-N curves of alloy-group C 1st region.

Ueda et al. ${ }^{16)}$ studied the fatigue strength of a twophase alloy in which the softer phase was enveloped by the harder phase, although $f$ was small. They showed an empirical relation between $\sigma_{\mathrm{w}}$ and $f$ where $\sigma_{\mathrm{w}}$ increased with increasing $f$ from $f=0$. Therefore, the range of 1st region is believed to be changed by the shape of the harder phase.

\section{Initiation and Propagation of Fatigue Crack in Plain Specimens}

When a load is applied, plastic deformation occurs in the softer phase at first as long as the elastic constants are not so different between two constituent phases. Upon the increase in the applied stress, plastic deformation begins to take place also in grains of the harder phase under the combined action of the applied stress and the internal stress caused by the discontinuity of plastic strain between two phases. When some constant stress is applied repeatedly on a specimen, average hysterisis loop of the softer phase differs from that of the harder phase. Following to the case of monotonic deformation, ${ }^{4,5}$ three stages in cyclic deoformation can be assumed, that is,

Stage $\left(1^{\prime}\right)$ : Only elastic strain is repeated in both phases.

Stage $\left(2^{\prime}\right)$ : Plastic strain is repeated only in the softer phase.

Stage $\left(3^{\prime}\right)$ : Plastic strain is repeated in both phases.

These stages, however, may not be precisely connected with three stages in static deformation. ${ }^{4,5)}$ For example, it may be possible that the situation of stage $\left(2^{\prime}\right)$ at the beginning changes to that of stage $\left(3^{\prime}\right)$, namely that slip deformation is induced in the harder phase by combined action of applied stress and internal stress produced by cyclic plastic deformation in the softer phase.

But, neglecting these minor problems, let us suppose the transition stresses, i.e., $Y(\mathrm{i})^{\prime}$ (from stages $\left(1^{\prime}\right)$ to $\left.\left(2^{\prime}\right)\right)$ and $Y(\text { ii })^{\prime}$ (from $\left(2^{\prime}\right)$ to $\left.\left(3^{\prime}\right)\right)$. When

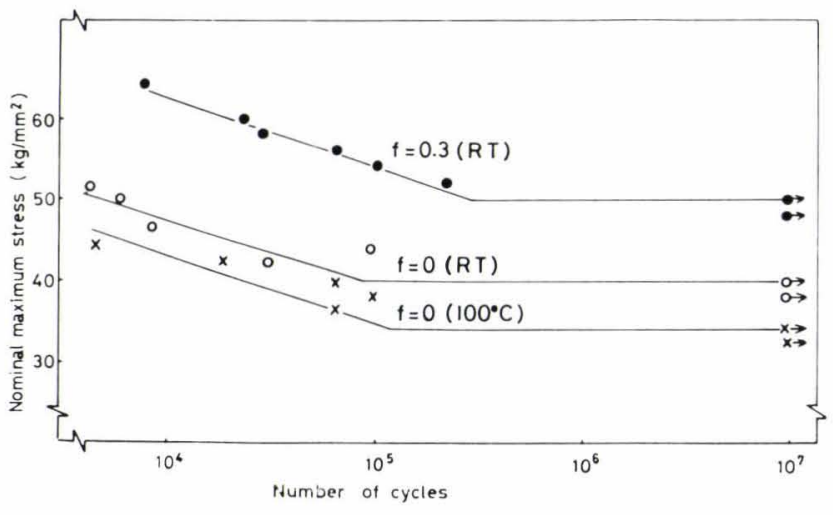

Fig. 5. S-N curves of alloy D

\footnotetext{
* Figure 5 is presented to show the effect of the shape of the harder phase on S-N curves. But, these results may be caused by combined action of martensitic transformation during fatigue test, fine grain size (see Photo. 1) and the presence of the harder phase. Austenite in alloy $D$ was metastable at $\mathrm{RT}$ and a little amount of martensite was induced during fatigue test. Then, the $\mathrm{S}-\mathrm{N}$ curve at $100^{\circ} \mathrm{C}(>\mathrm{Md})$ is shown in Fig. 5 for reference. It seems that the effect of martensitic transformation during fatigue test was small at RT. Similar conclusions have been obtained by Suto and Kaga, ${ }^{13)}$ and by present authors ${ }^{18)}$ using $\mathrm{Fe}-\mathrm{Ni}-\mathrm{C}$ alloys.
} 
stress amplitude $\sigma_{\mathrm{a}}$ is between $Y$ (i)' and Y (ii)' (mean stress is assumed zero), slip deformation occurs repeatedly only in the softer phase. Such a fatigue damage concentrated in the softer phase was already clarified by some experiments used X-ray technique and transmission electron microscopy. ${ }^{19,20)}$

In order to discuss whether the assumption of transition stress can be justified or not, next two reports are available. The conclusions by Yamada, et al. ${ }^{11}$ ) on the fatigue strength of ferritic-martensitic twophase alloys which belong to the 3rd region as mentioned before, are as follows.

The $\sigma_{\mathrm{w}}$ was concluded to be defined as the critical stress at which the fatigue cracks initiated in ferrite started to propagate into surrounding quenched structure of martensite, and so on. When $\sigma_{\mathrm{a}}$ was beyond $60 \mathrm{~kg} / \mathrm{mm}^{2}$, cracks initiated in the quenched structure caused final fracture before cracks in ferrite grew sufficiently large. In the quenched structure, fatigue cracks were observed at $\sigma_{\mathrm{a}}>40 \mathrm{~kg} / \mathrm{mm}^{2}$. Thus, $Y$ (i)' is estimated to be below $\sigma_{\mathrm{w}}$ and $Y$ (ii) to be around $40 \mathrm{~kg} / \mathrm{mm}^{2}$ in this steel. On the other hand, Ogiyama et al. ${ }^{15}$ ) observed that the crack initiation sites were different for the cases, $\sigma_{\mathrm{a}} \leqq \sigma_{0.2}$ and $\sigma_{\mathrm{a}}<\sigma_{0.2}$ in $\alpha-\gamma$ stainless steels. So, the above assumption seems to explain the results of these two reports. When $\sigma_{\text {a }}$ takes the value between $Y$ (i)' and $Y$ (ii)', fatigue cracks must be initiated in the softer phase or at the interface between two phases. On the contrary, fatigue cracks can start at slip bands both in the softer phase and in the harder phase when $\sigma_{\mathrm{a}}$ is beyond $Y$ (ii)'.

The conclusion by Yamada et al. on $\sigma_{\mathrm{w}}$ seems to hold in the present results of alloy A4 (3rd region's alloy). The critical condition at which fatigue crack in austenite propagates into surrounding ferrite grains must be influenced by aging, i.e., strengthening of ferrite phase.

Since the study of fatigue cracks in plain specimens of two-ductile-phase alloys in the 3rd region was previously reported, ${ }^{11)}$ only the results of alloy C3 in the 1 st region are presented here. Slip lines ob- served on the surface of a specimen at early stage of fatigue life were found to increase in number and some of them transfer to cracks with increasing the number of cycles. These aspect can be seen in Photo. 2.

Photograph 3 was taken from the specimen etched before the test, in order to clarify the relationships among slip lines, cracks and microstructure. It can be recognized that slip lines concentrate in ferrite phase and that plastic deformation hardly occurs in martensite. The density of slip lines in ferrite is extremely high in the vicinity of interfaces between ferrite and martensite. This may be caused by high local internal stress. ${ }^{4)}$ Then, when the strength of the interface is weak, fatigue crack may be easily initiated at the interface in order to relax the high local internal stress, instead of excess slip deformation in ferrite near the interface. In alloy C3 (both $600^{\circ} \mathrm{C}$ tempered and $200^{\circ} \mathrm{C}$ tempered), most of cracks were initiated at the slip bands. The growth of each crack was proceeded by propagating the individual crack or coalescing with another crack. It can be recognized that cracks propagate preferentially through ferrite

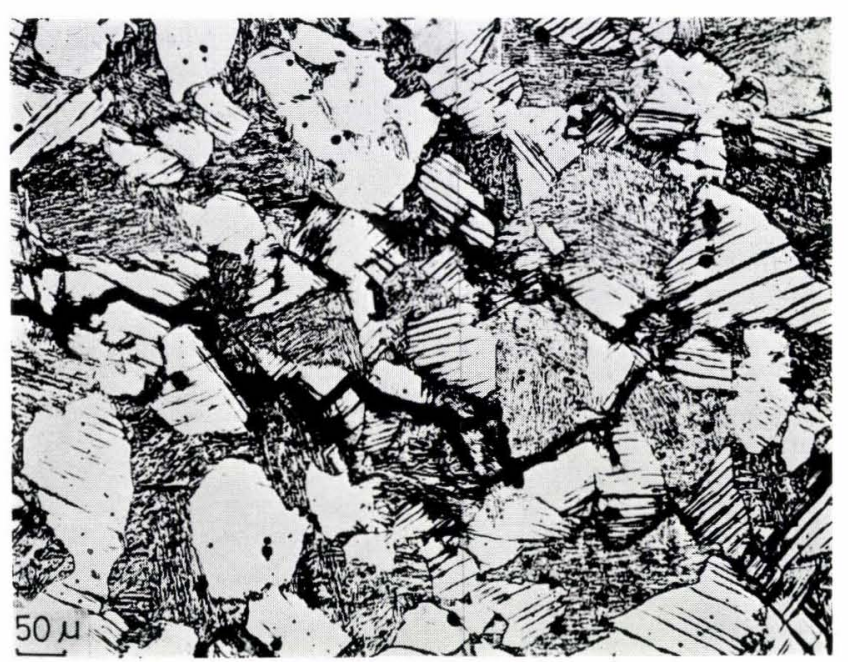

Photo. 3. Relationships among slip lines, cracks and microstructure in alloy $\mathrm{C} 3\left(600^{\circ} \mathrm{C}\right.$ tempered)

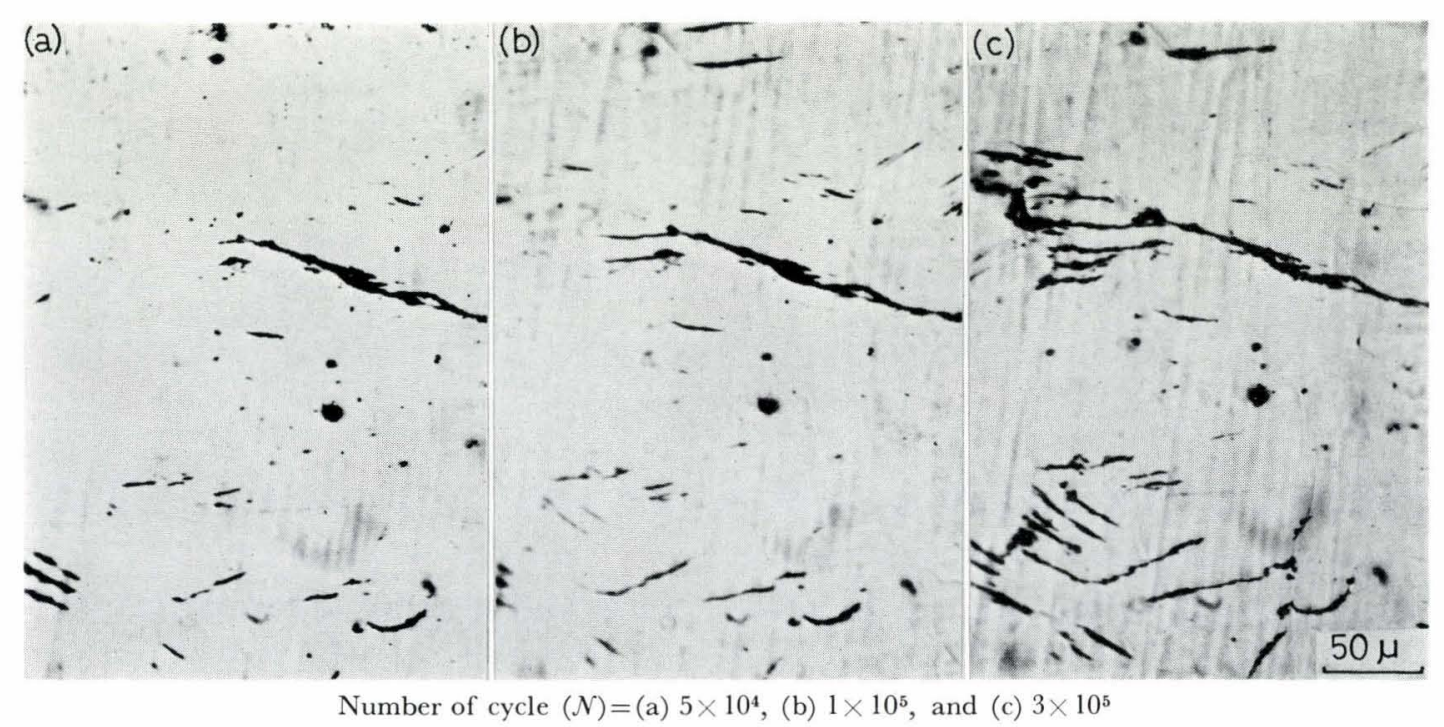

Photo. 2. Change in aspect on surface with repetition of applied stress $\left(24 \mathrm{~kg} / \mathrm{mm}^{2}\right)$ in alloy $\mathrm{C} 3$ (tempered at $600^{\circ} \mathrm{C}$ ) 
grains on the surface of a specimen as seen in Photo. 4 where the surface was slightly polished to remove slip lines and etched with nital. Although the cracks stopped at martensite grains were often observed, the cracks which propagated through martensite grains were scarcely observed. Photograph 5 shows the cross sections of specimens, the surfaces of which were plated with nickel before cutting. The features of these cracks are summarized as follows.

(1) All cracks observed were initiated in ferrite
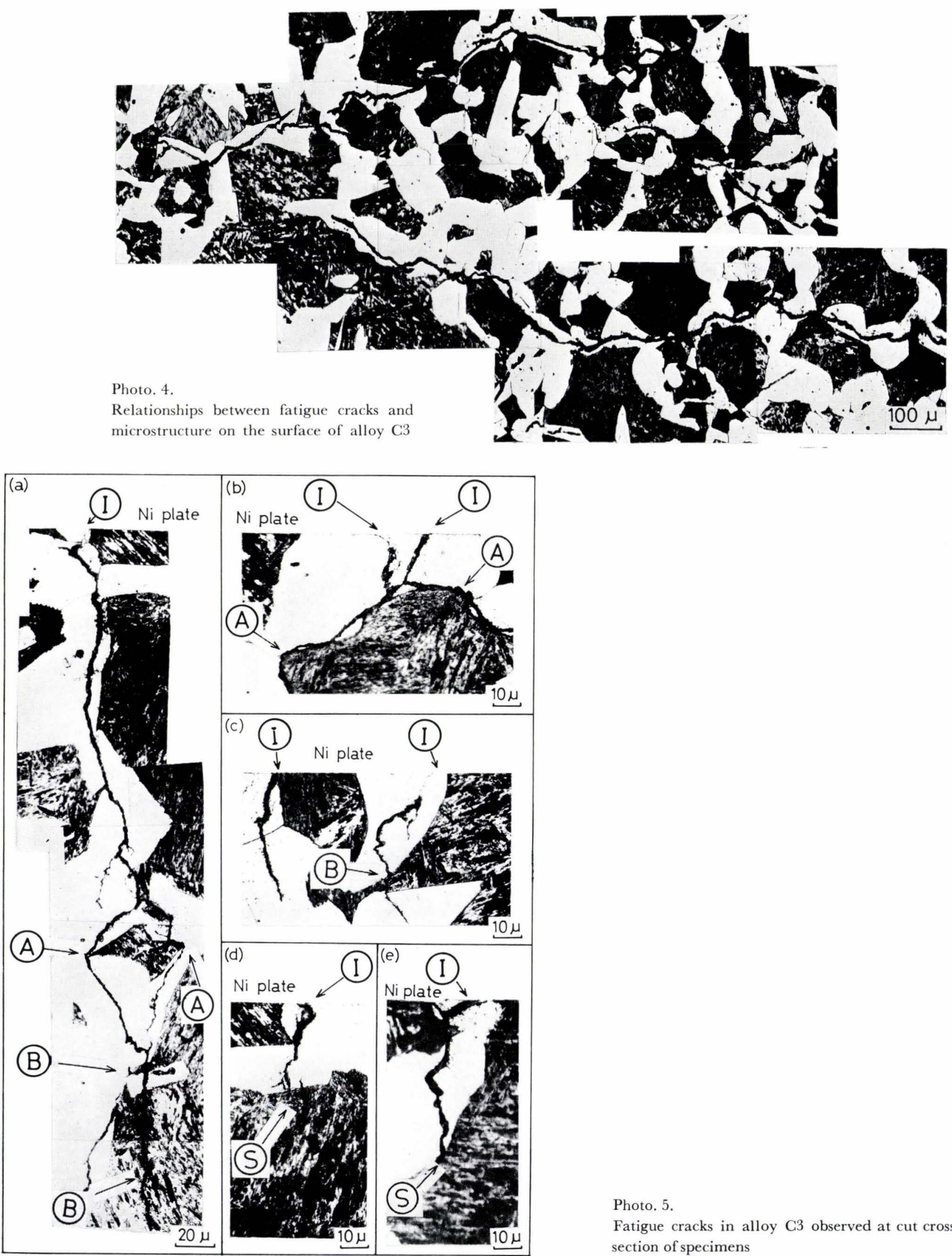

Photo. 5.

Fatigue cracks in alloy C3 observed at cut cross section of specimens 
phase (mainly in the vicinity of the interface, as marked by (I) in Photo. 5).

(2) When the length of a crack was short and approached a martensite grain, it frequently grew bypassing around the martensite grain (marked by (A)).

(3) When a short crack happened to propagate into a martensite grain, the growth of the crack was stopped in most cases (marked by (S)

(4) Sometimes, the cracks were observed to cut through martensite grain only when the length of a crack was sufficiently large or when the thickness of martensite grain along the direction of crack propagation was thin (marked by (B)).

Although it is of course desirable to show the threedimensional topology of a crack, next conclusion can be induced from two-dimensional observation (on a surface and on a cut cross section). The fatigue crack propagates through ferrite grains at the beginning of its growth in alloy C3 (both in $600^{\circ} \mathrm{C}$ tempered specimens and $200^{\circ} \mathrm{C}$ tempered ones). This feature of crack growth is the reason why $\sigma_{\mathrm{w}}$ dose not depend on $C^{*}$ in alloys of the 1st region (A2 or C3). A small amount of the harder phase may induce the zigzag manner in crack propagation but scarcely influences the value of $\sigma_{\mathrm{w}}$. This is why the lst region exists in $\sigma_{\mathrm{w}}-f$ relation.

On the contrary, in alloy $D$ or in alloys used by Ueda et al., ${ }^{16)}$ fatigue cracks in the softer phase must cut the harder phase for their propagation by all means. Therefore, $\sigma_{\mathrm{w}}$ depends on $f$ even when $f$ is small, so that the alloys with small $f$ belong to the 2 nd region.

Then, it is generally concluded that $\sigma_{\mathrm{w}}$ is defined as the critical stress or critical condition at which micro crack in a softer phase starts to propagate into surrounding area. This micro crack may be equivalent to the lst stage crack proposed firstly by Forsyth. ${ }^{21}$ ) This critical stress is changed by the route which is chosen for propagating path among the softer phase grain, the harder phase grain, grain boundary, and interface. Since this choice depends on $f$, shape of the harder phase and so on, $\sigma_{\mathrm{w}}$ depends on these factors.

\section{Crack Growth in Notched Specimens}

In the case of plain specimens, most part of fatigue life to fracture is consumed for the crack initiation and growth of the lst stage crack. ${ }^{21}$ ) Contrary to this, the importance of growth rate of the 2 nd stage crack $^{21}$ ) has been emphasized in notched specimens.

According to the results of alloys in the 1st region described in $I I I$. 2, fatigue cracks are initiated in the softer phase and propagate avoiding to cut through the harder phase at the beginning, so that $\sigma_{\mathrm{w}}$ is independent of the strength of the harder phase $\left(C^{*}\right)$. However, cracks having sufficiently large length were sometimes observed to cut through the harder phase. Then, it is interesting to study whether or not crack growth rate depends on $C^{*}$ in notched specimens.

Figure 6 shows examples of the relationship between crack length and repeated cycle in alloy C3. The relation between crack growth rate $(d 2 l / d \mathcal{N})$ and
$K_{\text {a }}$ where $l, \mathcal{N}$ and $K_{\text {a }}$ refer to a half of the crack length containing a central notch, number of repetition and stress intensity factor, respectively, is shown in Fig. 7. The value of $K_{\mathrm{a}}$ is calculated with the following equation:22)

$$
K_{\mathrm{a}}=\sigma_{\mathrm{a}}(\pi l)^{1 / 2}(\sec \pi l / W)^{1 / 2}
$$

where, $\sigma_{\mathrm{a}}$ : stress amplitude

$W$ : width of a specimen.

The linear relationship expressed by the well known equation, ${ }^{23)}$

$$
d(2 l) / d \mathcal{N}=A\left(K_{\mathrm{a}}\right)^{m}
$$

holds within some limited $K_{\mathrm{a}}$ region where $A$ and $m$ are constants (symbol $C$ is often used instead of $A$ in most papers ${ }^{23)}$ ).

As can be known from Figs. 6 and $7, d(2 l) / d \mathcal{N}$ depends on $C^{*}$. The value of $m$ in Eq. (2) is 3.9 for $200^{\circ} \mathrm{C}$ tempered specimens and 2.9 for $600^{\circ} \mathrm{C}$ tempered ones, respectively. Then, it is expected that $C^{*}$ influences the crack propagation mechanism. Photograph 6 shows the morphology of the surface of $200^{\circ} \mathrm{C}$ tempered specimens having a fatigue crack of $8 \mathrm{~mm}(2 l)$. Several parts around a crack are shown in these photographs (The indentations marked by

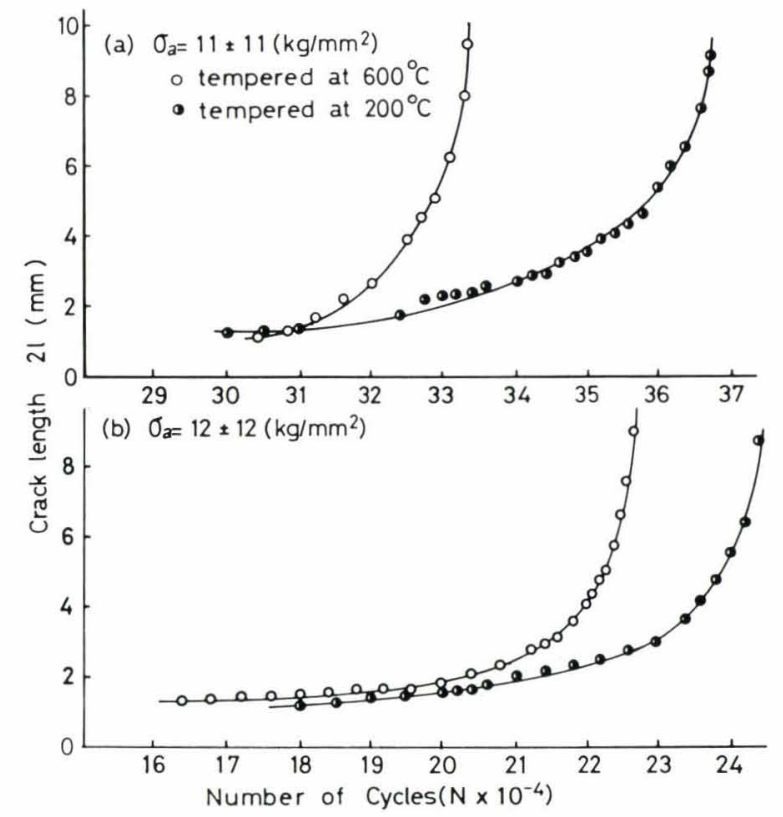

Fig. 6. Crack growth curves in notched specimens (alloy C3)

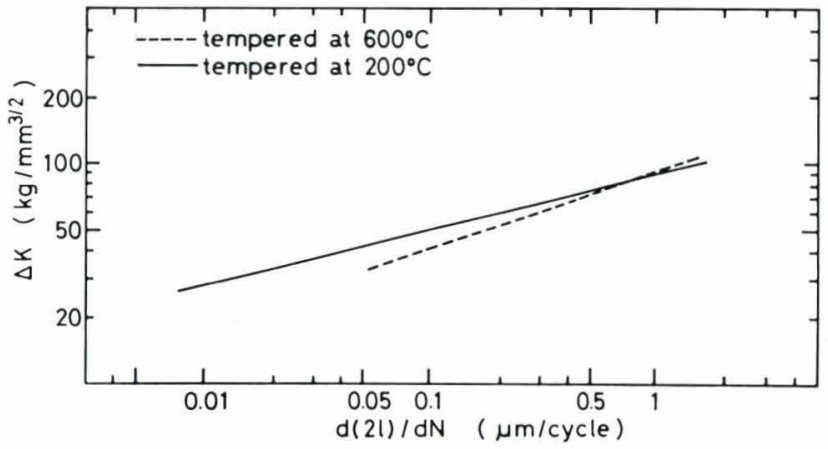

Fig. 7. Crack growth rate as a function of stress intensity factor $(K)$ 
Vickers hardness tester were used for recognition of the observed positions). It can be seen that slip lines concentrate in ferrite grains near a crack, which can be ascertained by comparing two micrographs for each set. That is, the bottom micrographs of Photo. 6 are the etched patterns of the same areas as those of the upper ones. The region where slip lines can be observed becomes wider with increasing the distance from the central notch $\left(l^{*}\right)$. The slip lines were hardly observed in martensite except at the narrow region in the vicinity of a crack of large $l^{*}$. It is clear that crack propagates in zigzag manner preferentially through ferrite at the beginning.

Contrarily to this, a crack in $600^{\circ} \mathrm{C}$ tempered specimen (about $2 l$ of $6 \mathrm{~mm}$ ) propagates somewhat straight as can be seen in Photo. 7. The region where slip lines are observed in martensite was wider in $600^{\circ} \mathrm{C}$ tempered specimen than in $200^{\circ} \mathrm{C}$ tempered one, while that in ferrite was almost the same.

At some length $(\mathrm{Lm})$, a crack begins to cut marten-
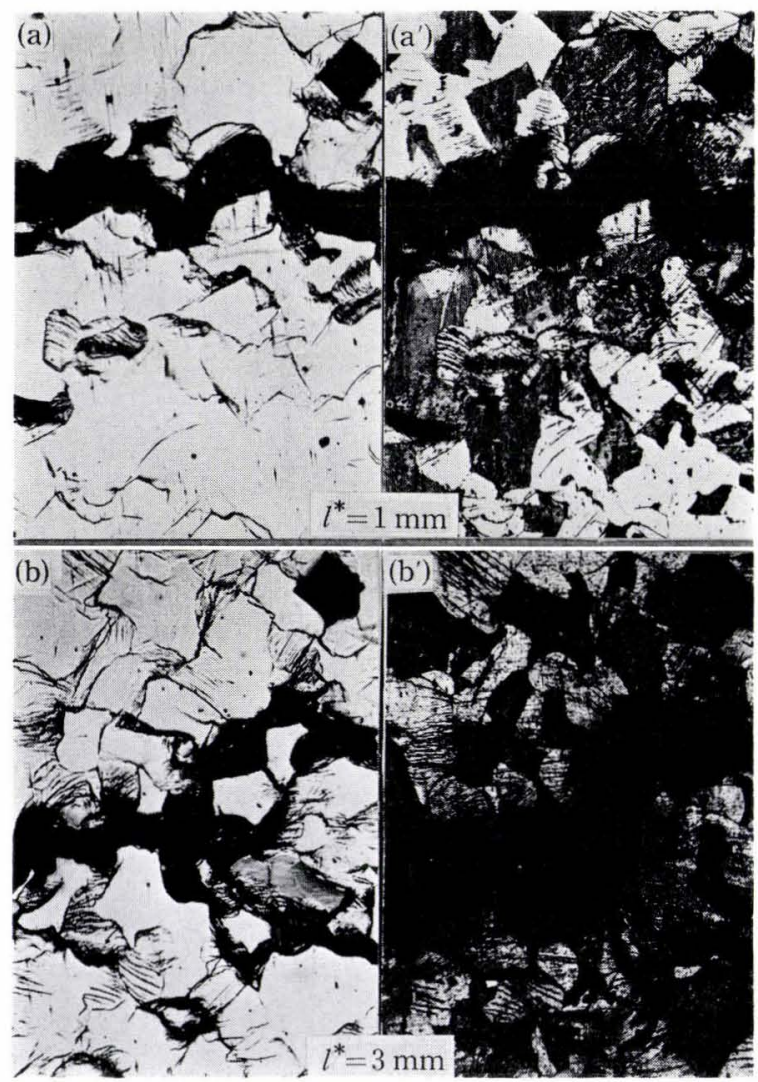

site grain to propagate. Though precise measurement of $L m$ was not carried out, the value of $L m$ in $200^{\circ} \mathrm{C}$ tempered specimens seemed to be larger than that of $600^{\circ} \mathrm{C}$ tempered ones. These features were obtained from the surface observation.

The crack propagated at the internal part of a specimen is shown in Photo 8 which was taken by polishing the specimen surface repeatedly (the final thickness of the specimen was almost one half of the initial). An internal crack is relatively straight and $\mathrm{Lm}$ is smaller in each case $\left(200^{\circ} \mathrm{C}\right.$ tempered or $600^{\circ} \mathrm{C}$ ), when compared with a crack on surface. This may be caused from the different stress field at the crack tip between on surface and at internal part of a specimen. It seems that there exists some critical condition concerning the phenomenon whether a crack cuts the harder phase or by-passes. This two types of crack propagation must affect the rate of crack growth. The detailed discussion concerning the relations among crack growth rate, size of plastic zone, and stress distribution around a crack tip will be reported elsewhere.

\section{Fractographs}

Typical examples of fractographs of alloy-group A are shown in Photo. 9. It is clearly recognized that ferrite phase became brittle by age-hardening from a comparison between Photos. 9 (g) and (h) which show the final fractured part of fatigue specimens. Little difference can be found among Photos. 9 (a) to (c) and (e) which are consisted mainly of ductile striation. Thus, in the case of quenched alloys, the effect of $f$ on fracture surface is little. On the con-

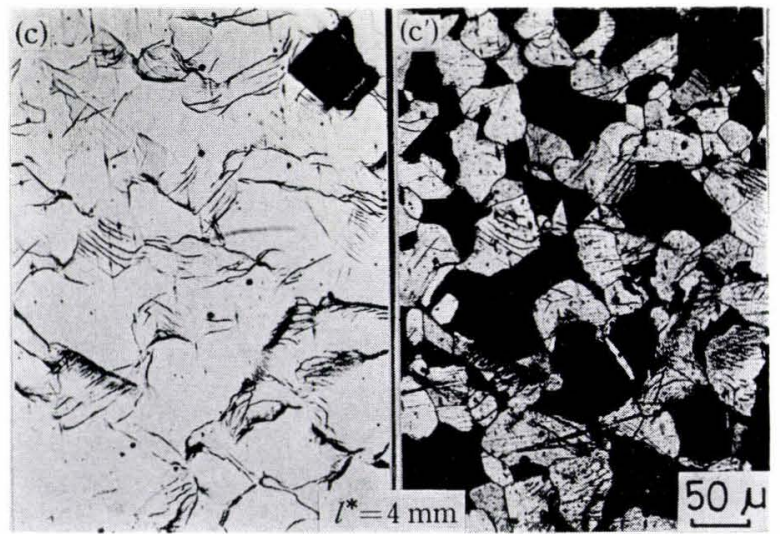

Photo. 6. Relationships among slip lines, cracks and microstructure in $200^{\circ} \mathrm{C}$ tempered notched specimen having a crack of $8 \mathrm{~mm}$ (including notch's length). The positions of photographs from the center of specimen are shown as $l^{*}$ and symbol "prime" refers to etched pattern.

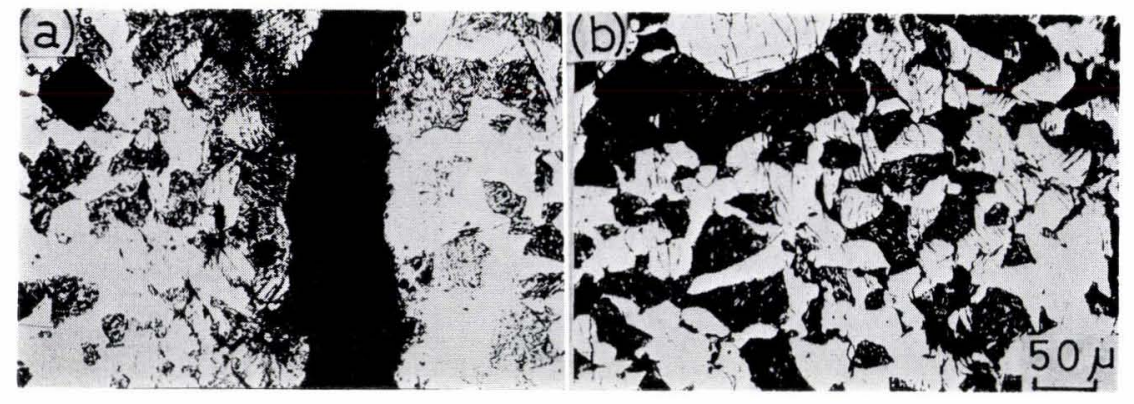

(a) $l^{*}=2 \mathrm{~mm}$

(b) $l^{*}=3.5 \mathrm{~mm}$

Photo. 7.

Relationships among slip lines, cracks and microstructure in $600^{\circ} \mathrm{C}$ tempered specimen (C3). The distances from the center of specimen are shown as $l^{*}$. 
trary, in the case of quench-aged specimens, the area of brittle pattern increases with increasing $f$, although it is difficult to distinguish austenite phase from ferrite phase on fractured surface clearly from Photos. 9 (b) and (d). On the other hand, in the case of C3, two types of pattern could sometimes be observed distinctively as shown in Photo. 10 (a). That is, the region of clear ductile striation seemed to be ferrite grain and the other region of mixed pattern with small dimple and striation, be martensite grain, as the latter was dominant in alloy C4.

On the fractured surface of notched specimen of alloy C3, aspects of fractograph changed with the distance from a notch. That is, crystallographic patterns (intergranular or slip fracture) as shown in Photo. 10 (b) were found at the fractured surface near a notch. Then according to the distance from a notch, striation, and next, mixed pattern of striation and dimple $\left(600^{\circ} \mathrm{C}\right.$ tempered specimens) or of striation, dimple, and brittle fractured surface $\left(200^{\circ} \mathrm{C}\right.$ tempered ones) as shown in Photo. 10 (d), were found.

\section{Conclusion}

Fatigue strength of two-ductile-phase steels was studied. The endurance limit $\left(\sigma_{\mathrm{w}}\right)$ depends on the volume fraction of the harder phase $(f)$, grain size $(\bar{d})$, the shape of grains and strength ratio $\left(C^{*}\right)$.

(1) When the shape of the harder phase grain is spherical, the effects of $f, \bar{d}$ and $C^{*}$ on $\sigma_{\mathrm{w}}$ are as follows.

(i) According to an increase in $f, \sigma_{\mathrm{w}}$ dose not change at first (1st region), then increases rapidly (2nd region) and again almost stops to change in the region near $f=1.0$ (3rd region).

(ii) In alloys of the lst region, $\sigma_{\mathrm{w}}$ is independent of $C^{*}$ while $\sigma_{\mathrm{w}}$ increases with increase of $C^{*}$ in alloys in the 2 nd or the 3 rd region.

(iii) With decreasing of $\bar{d}, \sigma_{\mathrm{w}}$ increases.

(2) The range of each region is changed by the shape or distribution of the harder phase. Alloys in which the softer phase is enveloped by the harder phase belong to the 2 nd region even if $f$ is small.

(3) Above conclusions (1) and (2) are explained by the characteristics of fatigue cracks. The $\sigma_{\mathrm{w}}$ is defined as a critical stress condition when a crack in a grain of the softer phase or at the interface starts to propagate into surrounding area. This is why the above three regions exist. Namely, in alloys of the 1 st region, the softer phase is chosen for the path of crack growth.

As such a preferential path of crack growth becomes less dominant against large cracks, the rate of crack growth measured in notched specimens depends on $C^{*}$ even in alloys of the 1 st region.

\section{Acknowledgements}

The authors are indebted to Prof. I. Tamura of Kyoto University for his helpful suggestion and Messers. K. Tanabe and K. Ozawa for their experimental assistance. They are greatful for the financial support of this work by Ishiwara-Asada Research Grant, The Iron and Steel Institute of Japan.

\section{REFERENCES}

1) H. W. Hayden and S. Floreen: Trans. ASM, 61 (1968), 474 \& 489; Met. Trans., 1 (1970), 489.

2) I. Tamura, Y. Tomota, Y. Yamaoka, A. Akao, S. Kanatani and M. Ozawa: Trans ISIJ., 13 (1973), 283.

3) Y. Tomota, K. Kuroki and I. Tamura: Tetsu-to-Hagané, 61 (1975), 107.

4) Y. Tomota, K. Kuroki, T. Mori and I. Tamura: Mater. Sci. Eng., 24 (1976), 85.

5) Y. Tomota and I. Tamura: Bull. Japan Inst. Metals, 14 (1975), 657

6) B. Karlsson and B. O. Sunderström: Mater. Sci. Eng., 16 (1974), 161.

7) M. Yodogawa and M. Tanaka: Tetsu-to-Hagané, 62 (1976), 1859.

8) T. Nakamura and K. Wakasa: Trans. ISIJ, 16 (1976), 134.

9) I. Tanimoto, S. Nemoto, Y. Tomota and K. Kuroki: Preprint of the annual meeting of Japan Soc. Mech. Eng., Nagoya, (1978), No. 783-2, 45.

10) H. Hayden and S. Floreen: Met. Trans., 4 (1973), 561.

11) K. Yamada, M. Shimizu, T. Kunio and H. Nakamura: Trans. Japan Soc. Mech. Eng., 34 (1968), 34 and 35 (1969), 1653.

12) H. Nishitani and S. Nishida: J. Japanese Soci. Strength and Frac. Mater., 5 (1970), 84.

13) H. Suto and H. Kaga: J. Japan Inst. Metals, 37 (1973), 1158.

14) S. Kumagai, T. Masumoto and Y. Imai: Preprint of Symposium on Retained Austenite, Japan Inst. Metals, (1972).

15) H. Ogiyama, Y. Soyama and I. Tamura: Preprint of annual meeting of Soc. Mater. Sci. Japan, (1974).

16) A. Ueda, M. Zama and K. Nakano: J. Japan Inst. Metals, 28 (1964), 269.

17) Y. Tomota and K. Kuroki: J. Fac. Eng. Ibaraki Univ., 24 (1976), 1 .

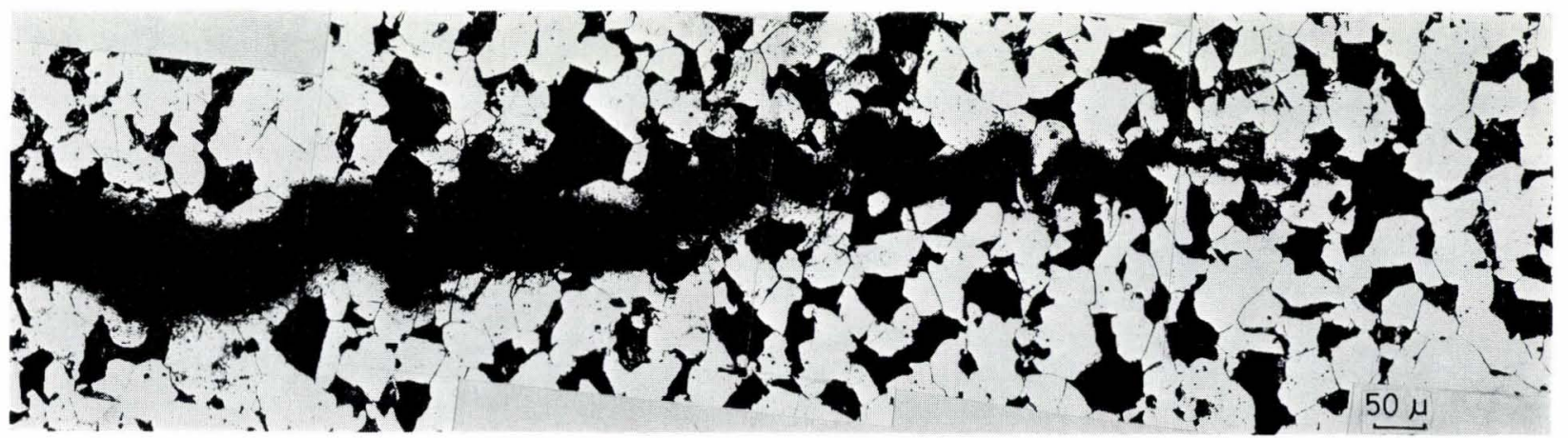

Photo. 8. Relationship between crack and microstructure of $200^{\circ} \mathrm{C}$ tempered notched specimen (C3) observed at cross section 

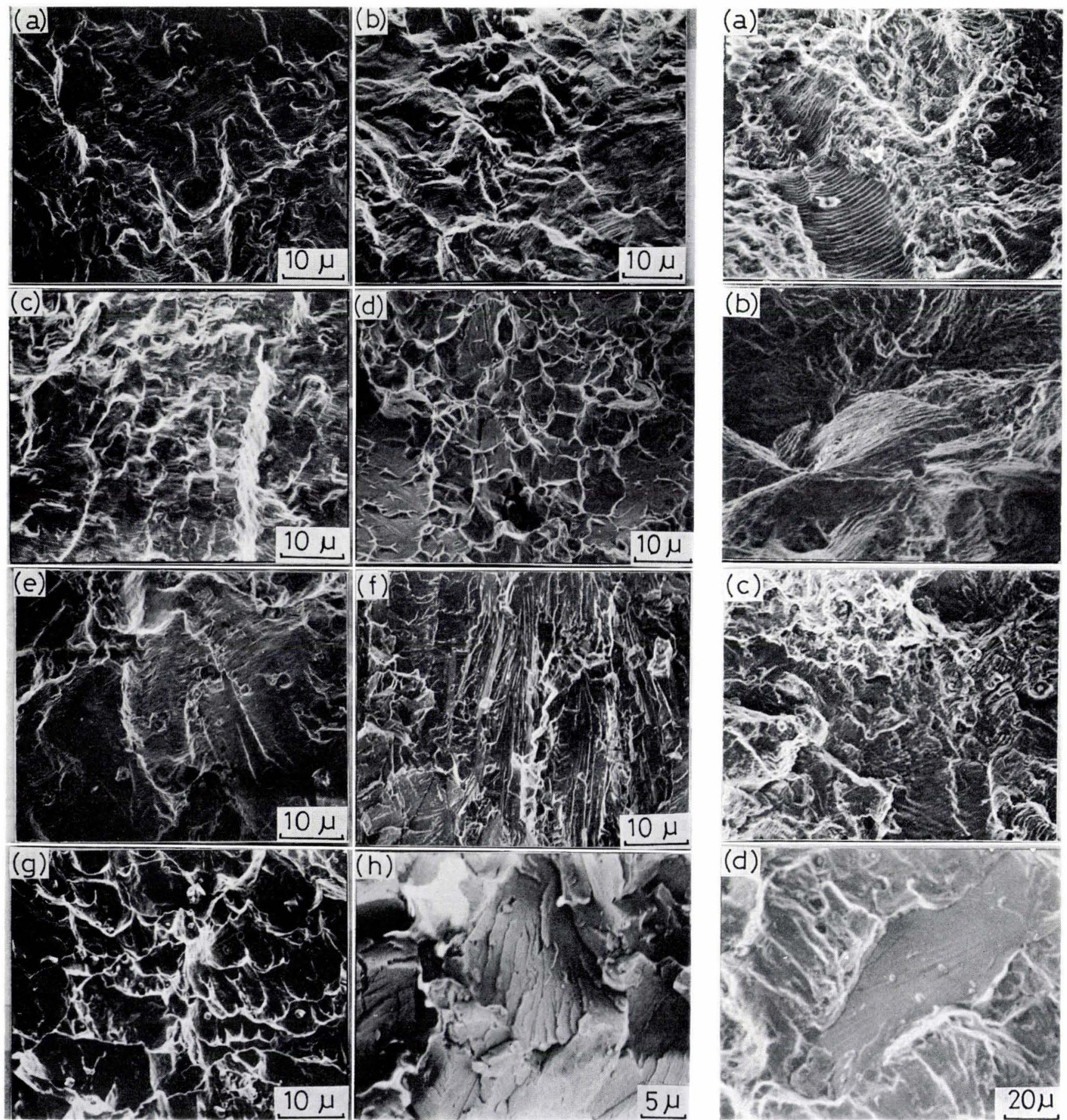

(a), (b): A2; (c), (d): A4; (e) (h): A5

(a), (c), (e), (g): Quenched specimens $\left(C^{*}=3.2\right.$

(b), (d), (f), (h): Quench-aged specimens $\left(C^{*}=6.5\right)$

Photo. 9. Electron fractographs of fatigue-fractured surfaces in alloy-group A
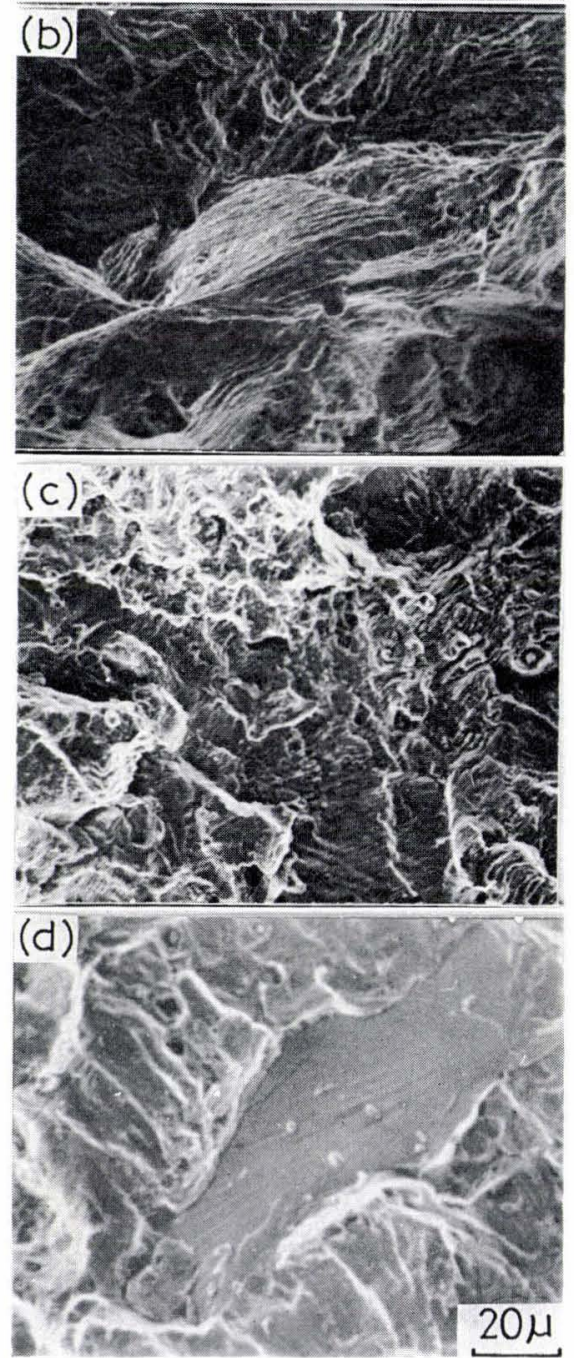

(a) Plain specimen $\left(600^{\circ} \mathrm{C}\right.$ tempered)

(b), (c): Notched specimen $\left(600^{\circ} \mathrm{C}\right)$

(d): Notched specimen $\left(200^{\circ} \mathrm{C}\right)$

Photo. 10 Electron fractographs in alloy C3

18) Y. Tomota, K. Saga, K. Tanabe and K. Kuroki: J. Fac. Eng. Ibaraki Univ., 24 (1976) 9.

19) T. Konaga and K. Honda: J. Soc. Mater. Sci. Japan, 16 (1967), 978.

20) Y. Imai and S. Kumagai: J. Soc. Mater. Sci. Japan, 20
(1971), 1292.

21) P.J.E. Forsyth: Acta. Met., 11 (1963), 703

22) C. E. Feddersen: ASTM Special Publ., 410 (1966), 77.

$23)$ P. C. Paris and F. Endogan: Trans. ASME. Ser. D, 85 (1963), 528. 